\title{
The Art Through the Media in the Conditions of the COVID-19 Pandemic
}

\author{
Luchia Angelova, Bozhidar Angelov \\ Faculty of Educational Studies and the Arts, Sofia University "ST. Kliment Ohridski", \\ Bulgaria \\ Изкуството чрез медиите в условията на пандемията COVID-19 \\ Лучия Ангелова, Божидар Ангелов \\ Факултет по науки за образованието и изкуствата, Софийски университет „Св. \\ Климент Охридски”, България
}

\begin{abstract}
Author Note
Luchia Angelova (D) https://orcid.org/0000-0001-7823-3515

Bojidar Angelov (D. https://orcid.org/0000-0001-9162-1766

The authors have no conflict of interest to disclose.

Correspondence concerning this article should be addressed to Sofia University,

Faculty of educational studies and arts, Sofia, 69A Shipchenski prohod Str. Email:

luchiamangelova@gmail.com, or bojidar.angelov1@gmail.com
\end{abstract}

\section{Бележки за авторите}

Лучия Ангелова https://orcid.org/0000-0001-7823-3515

Божидар Ангелов $\underline{\text { https://orcid.org/0000-0001-9162-1766 }}$

Авторите нямат конфликт на интереси.

Кореспонденцията, свързана с тази статия, да се адресира до Лучия Ангелова, Софийски университет „Св.Св. Климент Охридски, Факултет по науки за образовението и изкуствата, София, ул. Шипченски проход 69 A. Email: $\underline{\text { luchiamangelova@gmail.com или bojidar.angelov1@gmail.com }}$ 


\begin{abstract}
In kindergarten and primary school, the aesthetic perception and aesthetic attitude to the world, as components of aesthetic culture are formed through a cycle of artistic and aesthetic activities. children's audience in the context of the COVID-19 pandemic The question is answered, what do we need to know about the media in order to be able to live in accordance with the modern information society? It is pointed out that the task of media pedagogy is to specify where the interactions between the media and people - especially children, intervene by educating, educating and advising, orienting and informing despite the new conditions of the COVID-19 pandemic.
\end{abstract}

Keywords: art, esthetic culture, COVID-19, media pedagogy

\title{
Резюме
}

В детската градина и началното училище естетическото възприемане и естетическото отношение към света, като компоненти на естетическата култура се формират чрез цикъл от художествено-естетически дейности и възприемането на изкуството.В статията се акцентира на съвкупността от всички реални комуникационни взаимодействия, които медиите осъществяват всекидневно с разнообразната по състав детска аудитория в условията на пандемията COVID-19. Отговаря се на въпроса какво трябва да се знае за медиите, за да може да се живее съобразно модерното информационно общество? Посочва се, че задача на медийната педагогика е конкретно да посочва на кои места интеракциите между медиите и хората - преди всичко децата, се намесват, като възпитават и образоват, обучават и съветват, ориентират и информират въпреки новите условия на пандемията COVID-19.

Ключови думи: изкуство, естетическа култура, COVID-19, медийна педагогика

\author{
ARTICLE INFO: \\ Original Article \\ Received: 07, 12.2020 \\ Revised: 15, 01.2021 \\ Accepted: 04, 02.2021
}




\section{Изкуството чрез медиите в условията на пандемията COVID-19}

Прилагането на системен подход към проблемите на възприемането на изкуството и уточняването на възпитателните му функции е необходимост на общественото развитие. Ето защо нараства значимостта на диалектиката между психологическите, социологическите и социално-психологическите механизми. Изкуството е социален процес, защото е процес на общуване между хората, но това общуване се осъществява в рамките на груповите и междугруповите отношения. Междуличностните отношения по този начин опосредстват общуването с изкуството и в същото време са подложени на влияние и изменение от въздействието на изкуството. Тази диалектика показва, че нито една отделна страна от феномените на изкуството не може да бъде изследвана, без да се има предвид комплекса от обособени науки, без представата за целостта на изкуството да изчезне (Angelova, 2009). Диалектиката на тези процеси доказва и правомерността на подхода ни за изучаване въздействието на изкуството отделяйки сериозно внимание на динамиката на неговото социално съществуване и ролята на медийте. Сериозният анализ на общуването с медиите предполага отчитане на своеобразната нова култура, родена от техническите нововъведения. Формирането на тази нова култура е свързано с влиянието на технологични, демографски и разбира се икономически сили. Налице е един невероятен бум от дигитални продукти и услуги за деца, разпространявани чрез глобалната мрежа. Съвременното дете има достъп до редица електронни обучаващи системи, съобразени с възрастовите и психологическите му особености. Медиите в този нов контекст вече не се противопоставят на традиционната форма на съществуване на изкуството, а го превръщат в специфично условие за функционирането на медиите. В този връзка Д. Пейчева (Peicheva, 2011) представя по нов начин познатите медийни теории. Прави се извода, че съвременните медии, обвързани с Интернет, функционират в принципно нов тип времеви и пространствени измерения като се отличават с мигновено близко действие, интерактивност и комплексност. Тези нови по характер медии, които представляват микс от писмени, аудиовизуални и виртуални продукти, функциониращи като единно цяло предизвикват революционни промени в системата на културата. Това посредничество важи с особена сила за днешното общество обществото на 21 век, в което появата на нови медии и медийно детерминирани образувания е обичайно явление с усложняващи и едновременно с това улесняващи ефекти. Анализът на изследванията на връзката “медии - деца” в последните 30 години 
показва една трайна тенденция към организиране на конкретните емпирични изследователски проекти в трайна научна парадигма, свързана с медийната грамотност, медийната компетентност и медийното образование. Дигиталната грамотност е комбинация от компетентности изисквани за пълноценното участие в информационното общество. Тя включва знания, умения и поведение включващи ефективната употреба на устройства като смартфони, таблети, лаптопи и компютри за комуникация, изразяване, сътрудничество. С напредването на дигиталната революция технологиите стават все по-достьпни, компактни, удобни за употреба и от най-малките деца. Масовата употреба на устройства със сензорен екран и без хардуерна клавиатура доведе до преплитането на дигиталния и детския свят и поставянето на началото на едно ново детство. В този контекст на това ново детство се появи пандемията COVID19. За съжаление вече почти година децата и учениците са вкъщи и се обучават в електронна среда. Средата, която преди време е била отхвърляна в момента става желана заради пандемията - в свободното си време децата предпочитат да играят с приятелите си и да гледат телевизия. Онова, което било твърде далеч от заниманията им се появява е четенето на книги и заниманията със спорт. Вярно е, че повечето деца се запознават със света на телевизията много преди да навършат училищна възраст. В годината едно дете прекарва средно около 900 часа в училище и около 1023 часа пред телевизора. Телевизията може да изглежда и като нещо добро: детето може да получава помощ от образователните програми; да учи азбуката от телевизията; да опознава дивия свят на природата. Несъмнено - телевизията може да бъде добър учител и домакин, ако се гледа едновременно от родителите и децата и то особено сега в условията на пандемията COVID-19. Но въпреки нейните преимущества, телевизията може да бъде пагубна:

1. Съвременните проучвания показват, че онези деца, които нормално прекарват повече от 10 часа седмично, гледайки телевизия, са предразположени към наднормено тегло и са по-агресивни;

2. Деца, които гледат екшън сцени (като отвличане или убийства) са склонни да вярват, че светът е страшен и, че нещо лошо ще се случи и на тях;

3. Проучванията показват също така, че телевизията би могла да подсилва и расова дискриминация.

Деца под двегодишна възраст би трябвало да не гледат телевизия, а поголемите деца трябва да прекарват пред телевизора не повече от 2 часа на ден, според 
препорьките на Американската академия по педиатрия. Те препоръчват също родителите да наблюдават съдържанието на гледаните от тяхното дете телевизионни програми и да поставят определени граници, за да са сигурни, че детето не прекарва цялото си свободно време гледайки телевизия, вместо да се занимава с други дейности, като игра с приятели, упражнения и четене на книги. И тук не може да не споменем Марк Пренски. Мисията му е да постави учениците в истинския център на образованието. В лекцията си "Образование, чрез което техният свят да стане по-добър. Освобождаване на силата на децата от XXI век" на конференцията "Образование за професиите на бъдещето" (12.04.2017 г., София) той очерта идеите си как днешните ученици трябва да стигнат до бъдещето с развит потенциал и опит вместо със знания от вчерашния свят. За него тези игри не означават непременно, че децата се обучават в насилие. Всичко зависи от характера на съответните игри. Даде примери с деца, които вече имат постижения в науката, които създават мобилни приложения и имат идеи как да се борят срещу обществени проблеми като тормоза в училище и домашното насилие. Как обаче да запазим и развием вдъхновението им? Немалка част от тези игри не са част от официалната педагогическа култура. Децата ги научават в неформално обкръжение - често те са по-добре подготвени от учителите. Според него съвременният свят прави децата много по-бързо "овластени" - отрано се научават да боравят с различен вид технологии, да развиват практични умения, да имат желанието да усъвършенстват околния свят, да поставят под въпрос правилата около себе си. Казано накратко, М. Пренски смята, че по-скоро ние трябва да ги настигнем, отколкото те нас (Prensky, 2011). Учителите и родителите са част от култура, за която компютрите вече не са нещо ново въпреки, че са интегрална част от тяхното мислене - идеята за първите седем години. За тях компютърните игри са несериозно занимание - сериозно е, ако компютрите се използват например за писане на домашни, а това отговаря на ситуацията, в която сме поставени всички - пандемията COVID-19. Изследване в Германия (Bauer, 2016) - за децата между 6 и 13 години показва, че компютърните игри се налагат като най-интересни. Целта е да се разкрият във връзка с новите медии онези понятия, които се отнасят до "критично потребление на медии", от една страна, или критична "медийна компетентност", от друга. Компенсаторните концепции в практическата медийна педагогика преследват интереса за предаване на знания и умения по такъв начин, че учащите да намерят „връзката“ към (технологичните) разработки, за да компенсират или предотвратят възможни недостатъци. За Т. Bauer 
(2016) медийното образование е теоретичен и практически дискурс за медийната култура. Това е отваряща перспектива за критичния анализ на социалните отношения. Изображенията, които децата възприемат могат да ги травмират и да ги накарат да се чувстват уязвими. Проучвания показват, че децата между 2 и 7 години са ужасени от фантастични, страшно изглеждащи неща като чудати чудовища например. Просто казвайки на деца, че тези изображения не са истински няма да им помогнете, защото децата не могат да направят разлика между фантазия и действителност. Децата между 8 и 12 години са ужасени от заплахата на насилието, природни бедствия и измъчването на други деца, независимо дали тези изображения се появяват във филм, по новините или в развлекателни предавания, базирани на действителността. Тук изкуството влиза в ролята своеобразен медиатор или посредник между него и медиите в новите условия на пандемия т.е. ролята му нараства неимоверно. Така на преден план излизат проблемите, свързани със социалнопсихологическите, психолингвистичните, социолингвистичните, социологическите и педагогическите аспекти на връзките и отношенията, възникнали при взаимодействията на децата с изкуството, но вече в условията на COVID-19. Те отразяват преди всичко степента на задоволеност на потребностите и интересите на децата от възприеманата от различни източници художествена информация. Поконкретно казано, тези връзки и отношения отразяват ролята на изкуството за социализацията и подготовката за включване на децата в различните сфери на обществения живот в новата социална ситуация. Освен това на общосоциално равнище, ролята на художествената информация и художествената комуникация е необходимо да се изследва и изучава и по отношение на социалната активност на децата, но в условията на пандемията COVID-19.

Така наред с практическата насоченост, поставяме и някои теоретични проблеми свързани с изясняване на определени типове взаимодействия на различните възрастови групи деца (3-7 години, 7-11 години и отчасти 11-14 години) свързани с художествена информация(Angelova, 2016). В това отношение интерес представлява въпросът за функциите, които примерно, дори и отделните медии осъществяват по отношение на изкуството и децата за разлика от нас възрастните (Ангелов, 2016). Анализирайки пътя на детето към живота в семейството му и сред по-големите социални групи, към които то трябва да се причисли и да изпълнява съответни социални роли, става ясно, че този процес на усвояване на правилата и нормите включва различните системи на културата - език, морал, познание, философия, 
религия, обичаи и т.н. В процеса на социализация, при усвояването на културата, детето се съотнася не само с едни или други социални роли, но и с особен вид абстрактно-персонифицирани представи, съзвучни с неговите собствени личностни ориентации. Във връзка с това проведохме изследване чрез анкети и теста на Р.Жил насочени към установяване ролята на семейството при контакта на децата с изкуството и художествената информация в условията на пандемията COVID-19. Методиката на Рене Жил е предназначена за изследване на децата от 4-12 години (Angelova, 2018). Простотата и схематичността я отличават от другите проективни методики по лекотата при изследване и възможността за по-прецизна количествена и качествена оценка. Тя не може да се отнесе само към проективните. При нея има съчетаване с анкетата - едно преимущество при задълбочено изследване на личността.

Целта ни беше изследване на социалната приспособимост на детето, неговите междуличностни отношения и особености, неговото възприятие на вътрешносемейните отношения и някои характеристики на поведението му. Методиката позволява да се прояват конфликтните зони в системата на междуличностните отношения на детето, даващи възможност да се въздейства върху тези отношения, с влияние върху перспективното развитие на детската личност. Детето разглежда рисунките, отговаря на поставените към него въпроси, показва избраното за себе си място на изобразената картинка, разказва как би се държало в една или друга ситуация или избира един от описаните варианти на поведение. С въпросите към детето му се предлага да избере типичната форма на поведение. Така методиката позволява да се получи информация за отношението на детето към други хора, които го заобикалят семейството и друго обкръжение, както и към някои събития. Психологичният материал описващ системата на междуличностните отношения на детето, може условно да се раздели на две групи:

А. Промени, характеризиращи конкретно-личностните отношения на детето към другите хора:

1. отношение към майката

2. отношение към бащата

3. отношение към майката и бащата като към семейна двойка

4. отношение към братята и сестрите

5. отношение към баба и дядо, и други близки възрастни роднини

6.отношение към приятеля (приятелката)

7. отношение към учител (възпитател) 
Б. Промени, характеризиращи особеностите на самото дете:

1. любознателност

2. стремеж към общуване с големи групи деца

3. стремеж към доминиране, лидерство в детската група

4. конфликтност, агресивност

5. реакция на фрустрация

6. стремеж към усамотяване

Оказва се, че в свободното си време децата предпочитат да играят с приятелите си и да гледат телевизия. На второ място посочват четенето на книги и заниманията със спорт. Като истински рожби на съвременността децата ползват преди всичко компютър и не си служат с радиоприемник и касетофон. Половината от анкетираните посочват, че четат детски списания. Предпочитат списанието „Бърборино” и комикси. Най-вече гледат анимационни филми, детски и спортни предавания, предавания за животни. Любими предавания са популярни серийни филми по Disney Channel, като Сой Луна, Виолета и др. „Диви и опасни”, „Зоополиция”, испанският сериал „Щурите съседи”. Родителите посочват, че именно любимите предавания са основание за гледане на телевизия. Вниманието на децата не е изцяло ангажирано от екрана - в повечето случаи, гледайки, правят и нещо друго. От сателитните програми предпочитани са Boomerang, Jemix, Cartoon Network, Wild, Супер 7, Discovery и Animal planet, т.e. канали с анимационни и научнопопулярни филми.

Родителите не позволяват на децата си да гледат предавания, неподходящи за възрастта им и филми на ужасите.

Анкетираните споделят, че за последните месец не са посещавали и водили децата си на театър, по обясними причини. От анкетата разбираме, че децата очакват да ходят на театьр, единствено, когато това се организира от училище. От теста на Рене Жил личи, че театьрът не е свързан с някакви положителни преживявания за децата. Това се потвърждава от избора им на място в театралната зала - всички се идентифицират с хора, седящи по-назад, в чиято поза се долавя откровено отегчение.

Родителите не си спомнят да са водили децата си на художествена изложба. Тук също се разчита на училището - при екскурзии в различни градове се посещават местните изложбени зали и музеи.

Аналогични са и отговорите на въпросите, отнасящи се до посещения на киносалоните. Филмите, които се споменават са чрез телевизионно излъчване. Любими 
филми на децата са „Рапунцел и разбойникът”, „Карибски пирати”, „Алиса в страната на чудесата” и „Аватар”.

По-обнадеждаващи са резултатите, свързани с четенето на книги. Родителите твърдят, че децата им четат, макар че повечето не го правят всеки ден. Предпочитани са приказките и приключенските книги. Харесвани са и различните енциклопедии - за динозаври, животни, гори. Любими герои са Карлсон, Мечо Пух, Том Сойер, Снежанка, Пепеляшка и Пипи Дългото чорапче. Само едно дете обича да чете поезия. Децата обичат да гледат видеофилми предимно на приключенска тематика. Посочените заглавия - „Сам вкъщи”, „Барби и трите мускетарки”, „Карибски пирати” „Индиана Джоунс” и „Джурасик парк” - говорят, че филмите, гледани на домашното DVD, също заместват ходенето на кино. Филмите, които си спомнят като последно посетени са “ Лигата на животните” , “ Замръзналото кралство “, “ Доктор Дулитъл” “ Цар Лъв “, “Как да дресираш дракон “ и др. Ходенето на кино е едно от забавните неща, които децата правят през студените зимни месеци и е свързано със място за срещи с приятели, което е доказателство за пряката зависимост на изкуството със социалните контакти.

Резултатите от анкетата могат да се определят като тревожни. Срещите на децата с изкуството са епизодични, като организирането им е оставено изцяло в ръцете на училището, но това е в условията на пандемията COVID-19. Видно е, че свободното време на децата е запълнено с компютърни игри, както самостоятелно, така и с връстници и гледане на телевизия. Това се потвърждава и от теста на Рене Жил, проведен с ученици. Едно дете седи на масата между Патиланчо и Жоро Бекъма, а останалите му приятели са всички главни персонажи от предаването „Пълна лудница” и някои анимационни герои. Добре познатите от филмите Спайдърмен, Гладиатор и Кинг Конг са на масата на друго дете. Недвусмислен е изводът, че телевизията активно се включва във „възпитаването” на подрастващите, но театърът и нефилмираните приказки и детски романи нямат участие. Едно дете се оказа изключително затруднено да напише кои герои седят с него. След много мислене написа единствено Пипи, Карлсон и Звяра (от Красавицата и звяра). Останалите места останаха празни. Посещението на музикални представления също не се е случвало скоро. Досега до музиката е преди всичко чрез медийните средства. Особено популярна сред анкетираните деца е платформата Tik Tok, която е свързана и с танцуване и заснемане на видеоклипове. Досега до класическа музика става единствено в уроците по музика в училище. 
Безспорно е, че семейството пренебрегва изкуството като фактор във възпитанието на детето и особено при преодоляването на агресивното поведение. Причините за това могат да се търсят в няколко посоки. Едната е, че самите родители не изпитват необходимост от културни развлечения - в детството им у самите тях не е формиран такъв интерес и естествено на свой ред те неволно следват начертания път, предавайки липсата на интерес на своите деца. Другата причина е селището, в което живее семейството. В по-големите градове възможностите за културен живот са много повече, отколкото в по-малките населени места. „Човек ако иска, намира начини” може да бъде прието като отговор само в известна степен, защото тук вече става дума за средствата, които се увеличават при едно пътуване до големия град. Факт е, че днес на преден план е грижата за посрещане на насъщните разходи в условията на пандемията COVID-19 и общуването с изкуството не е приоритет. Най-сьществено според нас обаче е, че самите родители дори и да имат финансовата възможност (както е в случая с анкетираните), нямат духовната потребност да отидат на театър, на изложба, на кино и няма да формират такава потребност и у децата си. Родителите са доволни ако детето им чете книги и резултатите му в училище са отлични. Трябва да признаем, че тези семейства не проявяват безразличие към децата си. Родителите разговарят с децата си, подробно се информират как е минал денят им, но не говорят за изкуство, не обсъждат прочетените книги, гледаните филми. Децата не можаха да кажат кои са любимите герои на родителите им. Една майка харесва Бихтер (от „Забранения плод”) и Веселин Маринов, един баща е „приятел” с Гладиатор и Кинг Конг, а друг - със Зоро и Индиана Джоунс, т.е. става дума за първични емоции, които едва ли ще формират у децата отношение към изкуството. Предполагаме, че резултатите от тази извадка не са изолиран случай и не са малко семействата, на които и през ум не им минава, че е полезно изкуството да заема определено място в живота на децата.

Социалните умения на детето зависят от външната социална информативност и от развитието на „Аз”-а. Детето възпроизвежда социалния си опит, разкрива богатството на социалните и културните реалности, действа в хармония с тях, като запазва своята идентичност и уникалност. При разкриване особеностите на възпитателните функции на изкуството не могат да се пренебрегнат и тези свързани с медиите. В този случай анализът е полезен и с това, че се разглеждат онези факти и закономерности в изкуството, които имат отношение и към разпространението му чрез 
масовите комуникации и променящи специфичната му същност. Трябва да подчертаем, че за да се разкрият тези функции, е необходимо не да анализираме отделни факти, а да си поставим задачата да търсим истинския предмет на познание на всяка отделна наука за медиите и изкуството, просто защото медията освен носител на информация е носител и на изкуство. От тази гледна точка, особено в условията на пандемията COVID-19 искаме да акцентираме върху социализиращото влияние на изкуството по отношение на децата от предучилищна и начална училищна възраст, именно като се разглеждат проблемите, свързани с художествената комуникация и образователните технологии във века на интернет, телевизията и киното.

\section{Използвана литература}

Angelova, L., Legkostup, P. (2009). Detsata i izkustvoto [Children and art]. Sv. Kliment Ohridski Publishing house.

Angelov, B. (2016). Mediyna $i$ komunikativna kompetentnost. Osnovi na mediynata pedagogika [Media and communicative competence. Basics of media pedagogy]. Sv. Kliment Ohridski Ohridski Publishing house.

Angelova, L. (2018). Art therapy and hyperactivity in preschool age. In B. Angelov, R. Engels-Kritidis, D. Kostrub, R. Osad'an (Eds.), Specific Issues of Contemporary Preschool Education in Bulgaria and Slovakia. (p. 323-332). St. Kliment Ohridski Publishing house.

Angelova, L. (2016). Aesthetic and artistic development in the conditions of kindergarten and elementary school. Integrative functions of art. In R. Engels-Kritidis, B. Angelov, D. Kostrub, \& Robert Osad'an (Eds.), Views of Contemporary Preschool and Primary Education in Bulgaria and Slovakia (pp. 417-428). Paido.

Bauer, T. (1997). Neue Medien und neue pedagogic. Die interoperation von medien und pedagogic. Zur transformation der Medienpedagogik [New media and new pedagogic. The interoperation of media and pedagogic. On the transformation of media education].https://www.academia.edu/847852/Neue_Medien_und_Neue_P\%C3\%A4d agogik_Die_Interoperation_von_Medien_und_P\%C3\%A4dagogik

Peicheva, D. (2011). Mediatized reality. SWU Publishing house.

Prensky, M. (2011). H. Sapiens Digital: From digital immigrants and digital natives to digital wisdom. Available from: http://www.innovateonline.info/index.php?view=article\&id=705 https://cnaclassesnearyou.com/ 